\title{
BMJ Open Challenges of university nursing transfer students in an Asian context: a qualitative study
}

\author{
Shirley S Y Ching, Lillian Weiwei Zhang, Gwendoline Yuanyuan Guan, \\ Kin Cheung
}

To cite: Ching SSY, Zhang LW, Guan GY, et al. Challenges of university nursing transfer students in an Asian context: a qualitative study. BMJ Open 2020;10:e034205. doi:10.1136/ bmjopen-2019-034205

- Prepublication history for this paper is available online. To view these files, please visit the journal online (http://dx.doi. org/10.1136/bmjopen-2019034205).

Received 11 September 2019 Revised 21 February 2020 Accepted 21 April 2020

\section{Check for updates}

(C) Author(s) (or their employer(s)) 2020. Re-use permitted under CC BY-NC. No commercial re-use. See rights and permissions. Published by BMJ.

School of Nursing, The Hong Kong Polytechnic University, Kowloon, Hong Kong

Correspondence to Dr Kin Cheung; kin.cheung@polyu.edu.hk

\section{ABSTRACT}

Objectives To explore the social and academic experiences of nursing transfer students' (NTSs) in an Asian context.

Design A descriptive qualitative study design using focus groups and individual interviews with Chinese NTSs. The data were transcribed verbatim and analysed by using qualitative content analysis.

Setting A university offering preregistration nursing programmes in Hong Kong.

Participants Chinese NTSs studying in a 3-year special pattern within a 5-year Bachelor of Nursing programme in a university in Hong Kong.

Results Four main categories were identified: 'expectations about study at the beginning of the programme', 'challenges during transition', 'coping by prioritising' and 'our world is small'. The NTSs had clear goals for becoming professional nurses and consequently aimed at higher academic achievements throughout the study. They anticipated enjoying university life at the beginning of their study; however, the challenges caused by heavy study workloads and transition from passive to independent learning approaches, compounded by the limited time of 3-year study, forced them to develop coping strategies to reconcile and prioritise their preconceived notions, academic pursuits, social engagements and personal well-being. Their high prioritisation of good academic performance confined their university lives to the small world of the academic arena.

Conclusions The study identified challenges faced by NTSs in adjusting to university study. Suggestions are offered to different stakeholders to address the issues at individual, institutional and government levels so as to enhance NTSs' learning experiences at university.

\section{INTRODUCTION}

Transfer from community college to university degree studies is one of the pathways to the nursing profession. ${ }^{12}$ In the USA in 2019 , $38.4 \%$ (approximately 140000 ) of baccalaureate nursing students were initially associate degree holders. ${ }^{3}$ Although this pathway is popular, little has been done to explore these nursing transfer students' (NTSs) learning experiences, particularly in Asian contexts. In a Canadian study of 13 NTSs, 5 transition issues were identified: transition stress,

\section{Strengths and limitations of this study}

- A qualitative approach was used to study the learning experiences of Asian transfer students' that have not been explored before.

- Rich descriptions of the students' learning experiences were collected through their interactions in an amiable setting in focus group and in-depth individual interviews.

- Trustworthiness of the findings was ensured through peer debriefing, keeping an audit trail, and rich description of the data.

- Subjective recall of experience and discussants' reluctance to discuss personal issues might have limited the data.

- Individual interviews might have hindered discussion and elicitation of ideas.

geographical relocation, academic shock, professional transformation, social life and adaptation. $^{1}$

Challenges faced by transfer students include transfer shock, ${ }^{4}$ declining academic results as reflected by Grade Point Average (GPA), campus culture shock ${ }^{56}$ and feelings of demotion. ${ }^{7}$ Universities might consider that mainstream and transfer students have the same needs, ${ }^{5}$ or even expect transfer students to have less adjustment-related needs because they have prior postsecondary education experience. Transfer students themselves might also overestimate the similarities between community colleges and universities and expect not to experience difficulties in the transition. ${ }^{5}$ However, these assumptions have been shown to be untrue and have caused transfer students to receive less adequate support or to need to seek help from the university. In western contexts, particularly in the USA, transfer students demonstrate higher levels of mental health distress ${ }^{6}$ than their non-transfer counterparts (often referred to as freshmen entrants in the literature), including difficulty meeting academic standards, increased stress related 
to their academic lives, difficulty in adjusting to changes in academic policies and a sense that they are competing with freshmen entrants. ${ }^{8}$ Heavy study workloads or graduation delays might ensue if their study credits are not accepted by the university. ${ }^{9}$

In eastern contexts, particularly the Chinese culture, education is valued highly and seen as the only pathway to success. ${ }^{10}{ }^{11}$ Eastern students usually aspire to continue their study from high school to university ${ }^{12}$ and to enter into full-time work after completing their education. ${ }^{101314}$ This means that, in addition to negative experiences similar to those experienced by western transfer students, those in Asia might have a sense of failure if their high school admission scores are not good enough to get into university ${ }^{15}$ because of pressure from their parents, peers and society. The universities in Hong Kong offer 5 -year preregistration nursing programmes. On graduation, students can apply for registration with the Nursing Council. Transfer students who are associate degree or higher diploma graduates (NTSs), with credit transfers, are admitted to a 3-year special study pattern to complete the preregistration nursing programmes. ${ }^{16}$ The purpose of this study was to explore academic and social aspects of NTSs' experiences in an Asian context.

\section{METHOD}

\section{Design and participants}

This was a descriptive qualitative study using focus groups. ${ }^{17}$ Focus group or individual interviews were conducted depending on the availability of the participants. Focus group interviews allow the participants to discuss complex subjects in an amenable setting, and facilitate them to reveal what they think and why they think what they do. ${ }^{17}$ Individuals are facilitated to form opinions of the topic by interacting with others, with individual participants supported and encouraged to be open in their responses. ${ }^{18}$ Individual interviews enable the interviewer to collect detailed accounts of participants' knowledge, thoughts, beliefs and attitudes, pertaining to a phenomenon. ${ }^{19}$ The participants were Chinese NTSs studying a 3-year Bachelor of Nursing programme in a university in Hong Kong. Purposive sampling was used to select NTSs who had graduated from 2-year community college studies and had been enrolled in their current programme for at least one semester. They were recruited through emails and in-class promotion. The interviews were conducted in a quiet room at the university.

\section{Data collection}

Twelve focus group and 4 individual interviews were conducted with 45 NTSs (9 male and 36 female; 14 year 1 , 13 year 2, 9 year 3 students, and 9 graduates). Their ages ranged from 18 to 25 . The groups were arranged according to the NTS' years of study; thus, they knew one another. Depending on the students' availability, each focus group consisted of 2-5 participants. The interviews lasted for 90-150 min, and each participant was interviewed once.
Table 1 Interview guide to explore the academic and social experiences of nursing transfer students

\section{General broad opening question}

1. Can you tell me about your experience studying in the university till now?

\section{Probing questions}

1. What do you think about your transition experience at the university?

2. What were you particularly hoping to gain from this programme? What have you actually gained from it?

3. What learning approach do you use?

4. Which aspect of teaching have you found most helpful, in getting to grips with the key subjectmatter? And which aspect is the least helpful?

5. How have you found your relationships with the staff/transfer students/non-transfer (mainstream) students? How about extracurricular activities?

The interviewer was a female researcher with experience in qualitative studies and with tertiary education. She was not personally acquainted with any participant, which might have affected the trustworthiness of the findings. The interviewer met the participants on the day of the interview. Each participant was given an information sheet. The interviewer explained the purpose, procedures, voluntary nature of the study, anonymity and the participants' rights to withdraw at any time without any impact on their courses before they signed the consent forms and agreed to keep the content of the interview confidential.

An interview guide was used (table 1). The interviewer moderated the interviews ${ }^{20}$ and started with a broad question, 'Can you tell me about your experience in the university?' Probing questions were asked, which allowed the participants to elaborate on their experiences and challenges. The interviewer facilitated discussion and interaction among the group members. ${ }^{21}$ All the interviews were conducted in Cantonese, the participants' first language, and digitally recorded. At least one research assistant joined each focus group as an observer and wrote notes on the participants' interactions. After each interview, debriefing sessions were held between the interviewer and the research assistant to note their impressions about the key issues discussed. The data collection and analysis occurred simultaneously. Data collection continued until data saturation, that is, when the interviewer ceased to find new information. When saturation was reached, a few more interviews were conducted to confirm. ${ }^{22}$

\section{Data analysis}

The audio recordings were transcribed verbatim in Chinese and then imported into NVivo Pro 12 for data management. Each participant was assigned a code using the interview number and an anonymous form of interviewee identification; for example, 13D means interviewee $\mathrm{D}$ of the 13th interview. The qualitative content 
Table 2 Summary of categories and subcategories

\begin{tabular}{ll}
\hline Categories & Subcategories \\
\hline Expectation at the beginning of the programme & Setting a clear goal to become a professional nurse \\
& Aiming at a high academic performance \\
Challenges during transition & Similarity between community college and university studies \\
& facilitated adjustment \\
& Heavy study workload but limited time \\
Coping by prioritising & Transition from passive to independent learning \\
& Understanding of curriculum arrangement \\
Our world is small & Prioritising of the scope of subject materials to study \\
& Prioritising based on the their goal and GPA \\
\hline
\end{tabular}

GPA, Grade Point Average.

analysis consisted of five steps. ${ }^{23}$ First, the interviewer, research assistant and researchers read and reread the interview transcriptions to become immersed in the data pools. Second, meaning units (sentences/ paragraphs) corresponding to different aspects of the students' experiences were selected using an inductive approach (eg, participants' description of their studying experience was labelled as 'Learning without teacher's reminders'). Third, every meaning unit was condensed and labelled with codes (eg, 'Required to learn independently'). Fourth, subcategories were identified and grouped by comparing their similarities and differences (eg, 'Transition from passive learning to independent learning'). Finally, four categories were identified (including 'Challenges during transition'; table 2). The interviewer and the research assistant inductively coded the first four interviews separately. Then, they discussed the coding to ensure agreement on a basic set of codes and categories. The subsequent interviews were then analysed by the research assistant using both inductive and deductive approaches. The research assistant, interviewer and the research team met regularly to reach consensus about the coding, to ensure credibility of the findings. The trustworthiness of the study was enhanced further by keeping an audit trail which ensured dependability and conformability of the findings. Transferability was maintained by providing contextual details and rich descriptions of the findings. ${ }^{24}$

\section{Patient and public involvement}

Patients or members of the public were not involved in this study.

\section{RESULTS}

Four main categories were identified (table 2).

\section{Expectations at the beginning of the programme}

In Hong Kong, the competition for admission to nursing programmes is very keen. Owing to the limited transfer places, the NTSs had to study very hard to compete for them.

\section{Setting a clear goal to become professional nurses}

The NTSs often had clear goals and high expectations of the nursing programme to prepare them to become professional nurses.

I hope I can be trained to become a professional during my study period. I will practice as a registered nurse after graduation. (13D, Year 1)

I want to be prepared mentally and equipped with good skills to become a nurse. (13B, Year 1).

The NTSs were well aware of the professional nurse's responsibility to promote patients' wellness and not to harm them. This awareness mobilised them to study hard. In addition to learning the subject content, the NTSs treasured the teachers' sharing of their beliefs and attitudes, which motivated them to achieve more.

We chose the nursing discipline. We are responsible for our patients. We are not studying just for ourselves...If we do not study hard now, we may cause harm to our patients...This is the most significant difference between nursing and other programmes. (01A1, Year 2)

Our teachers shared with us their experiences, beliefs and attitudes about patient care during the lectures. We know attitude is important. (01A2, Year 2)

The teachers had high expectations of us, encouraged us to achieve more and gave us a lot of advice... As a result, we had more motivation to improve ourselves. (21C, Year 3)

\section{Aiming at high academic performances}

Owing to the motivation to become professional nurses and the long-awaited opportunity to study nursing at university, the NTSs aspired to academic excellence at the beginning of their study. 
When we enrolled in university, we had high ambitions to achieve 4 (the highest GPA). We wished to learn more. (04A1, Year 2)

\section{Anticipating university life}

The university provides a wide variety of extracurricular activities that support students' personal development. The participants said they expected to enjoy university life, especially at the beginning of their study.

When we were admitted to the programme, we thought there would be less work and we could enjoy our university life. (04A2, Year 2)

\section{Challenges during transition}

The expectations about study and university life, combined with their clear goals to become competent nurses and the actual experience, created challenges for the NTSs' transition. The similar teaching modes in their subdegree institutions and the university facilitated their initial transition. However, the heavy study workload due to the shorter study period of 3 years, coupled with the passive and surface approaches to learning they had adopted in their community colleges, hindered their transition.

\section{Similarity between community college and university studies facilitated adjustment}

In their community colleges, the NTSs were exposed to lectures, seminars and skill practice similar to the university study mode. Shortly after admission to the university, many NTSs had not experienced any adjustment difficulties.

My classmates and I adjusted very quickly. The community college did very well to align the mode of teaching, learning and examinations with the university. (26A, Graduate )

It's easy because the study contents are similar. Maybe the study schedule in community college was very packed, so now it is more (relaxed)... (02A2, Year 2 )

We had practicum when studying in community college. There was no big difference compared with the first clinical placement in the university. (28S1, Graduate)

\section{Heavy study workload but limited time}

Although the teaching modes were similar, the shorter study period causes heavy study workloads for NTSs. Along with classroom learning, they are required to complete clinical hours, which are often scheduled during the semesters or summer breaks. This time pressure limits the NTSs' participation in university activities.

The (degree programme) schedule is very packed. We have to study many subjects each semester and go for clinical placement during semester breaks. We don't have much time to rest. (19B, Year 3)
We have to complete many clinical placements, projects and credits within a short time period. .... Compared to non-NTSs (in the 5 year programme), we have more workload ... and less time to attend extracurricular activities. We focus more on academic study. (21C, Year 3)

Time management has become a challenge for many NTSs.

Time management is difficult. Students are encouraged to engage in university life/activities. However, nursing study is tough. This is a big challenge because we still want to enjoy university life. However, we keep on studying and studying, just like in community college and secondary school. (14B, Year 1)

The NTSs assessed their workloads and responsibilities by comparing themselves with the 5 -year Bachelor of Nursing students and other bachelor programmes.

NTSs focus on the academic side so much, studying is the priority. The other Bachelor of Nursing students (in the 5 year programme) are more relaxed. They pay attention to academics while also balancing academic and other activities. (28S1, Graduate)

\section{Transition from passive to independent learning}

Another challenge frequently mentioned was the participants' approaches to learning and studying. In the community colleges, they had adopted rote learning and were only required to acquire a limited scope of knowledge. However, university study requires self-directed and independent learning, which created a sense of uncertainty for the NTSs.

In the community college, our teachers supported us more by reminding us of key points for revision. However, in the university, you have to learn independently. In nursing study, you have to learn everything and there are no "key" points. As a result, the workload is heavier than before. (14A, Year 1)

When studying in university, we have to make a lot of effort to get familiar with the subject content through reading online journals, .... Simply studying and reciting all the materials given by the teachers is no longer enough to prepare for the examination. Our stress is much increased. (07A, Year 2)

I have a sense of uncertainty when studying in the university and this causes stress. The scope covered in the examination is not confined to notes. The examination requires more than direct recitation of the notes...The exams in community college studies were straightforward, while they are not in the university. (07D, Year 2)

Some NTSs were used to 'spoon feeding' approaches to learning. The following interactive conversations illustrate that the gap in the approaches to learning and studying was difficult to overcome. 
Active learner, however...(05A2, Year 1) We are not used to it; we are not learning actively in the past. (05A3, Year 1) We used to learn in a one-way mode. (05A1, Year 1) That is 'spoon-feeding'. (05A5, Year 1)

The learning in university requires us to raise questions instead of telling us everything. However, I think the teachers can tell us more, instead of not telling us if we don't ask. (13A, Year 1)

Teachers expect active learning. We want to learn actively but we don't know how to do it. (14B, Year 1)

Influenced by passive learning and studying approaches, an NTS verbalised the need to have common lecture notes for classes taught by different teachers and standardised step-by-step assessment guidelines for skill examination, which was echoed by others in the same focus group

Strange. There are two classes of students taking the same subject but taught by two teachers. (21C, Year 3) Teaching contents were different. (21D, Year 3) Teachers have discussed the syllabus and teaching guidelines, but the details of teaching content and notes are different. (21C, Year 3) The notes for both classes should be the same. (21A, 21D, Year 3)

We want to have a universal guideline to be followed by everyone. For example, in wound care, the concept of asepsis is the principle and should not be violated. But different teachers using different steps for wound cleansing may not be following the sequence on the checklist. (02A2, Year 2)

\section{Coping by prioritising}

Understanding of curriculum arrangement

Understanding subject arrangements and restrictions helped the NTSs to persist despite struggling and needing to work hard.

The subject syllabus is fixed, especially the subjects specific to the nursing discipline. The school has restricted subject arrangements. Although the schedule is packed, the study plan is good enough. (28S4, Graduate)

The required number of hours for clinical practice is 1440 , which is more than the work-integrated education hours of the other disciplines. The clinical hours requirement is stipulated for nursing registration. (21A, Year 3)

\section{Prioritising of the scope of subject materials to be studied}

Most of the NTSs indicated that they were strategic in planning their study. They weighed the subject requirements, and then prioritised their time and effort. They decided to give up exploring more in-depth study or deep approaches to learning so as to review all the subject materials given by their teachers.

There is a lot of content in each subject. We do not have enough time to search for more information to study every topic in-depth .... I want to search for more information but there is no reason to spend several hours on it. (02A2, Year 2)

We do not have any days off on weekdays... If we focus on one subject, it is not fair to the other subjects. We need to accommodate the requirements of all subjects. (07A, Year 2)

\section{Prioritising based on their goals and GPAs}

Academic outcome (ie, GPA) was described as a priority for the NTSs, thus determining their study efforts.

I give up the self-directed active approach of learning recently. Even if I learn more, it won't help to increase my GPA. My classmates asked me why I still studied so much of the knowledge which would not be asked in the examination. We still learn by using an examination-orientated approach. Obtaining high grades is the priority. (09B, Year 1)

We want to improve our English but need to bear the cost of lowering the overall GPA if the grade for English is not good. (05A3, Year 1)

\section{Our world is small}

Owing to these challenges, some students spent most of their time catching up with their studies and sticking to passive surface approaches to learning. This approach resulted in mental exhaustion, and sacrificing participation in university activities, social life and community service.

\section{Mental exhaustion}

When admitted to the programme,. We wished to learn more .... But now, we just want to complete the programme because we are very much exhausted already. (04A1, Year 2)

The nursing study in the university is very demanding. ...We need to meet all the requirements. As a result, we will not have the ambition to achieve a higher GPA anymore. (04A2, Year 2)

\section{Limited exposure and enjoyment of university life}

The nursing students who are admitted directly from high school (ie, non-NTSs) have a big world. However, my world is really small. We are confined to the classroom. I have not explored the university, its culture, or even its facilities. I have not joined any student societies, met other students. ... (01A1, Year 2)

\section{DISCUSSION}

Our qualitative study has indicated that NTSs enrolled in the nursing programme tended to have a clear goal to become competent nurses. They were aware of the programme and nursing council requirements. From the academic perspective, they were mindful of active learning and their responsibility to learn nursing knowledge, skills and attitudes. They perceived their transition between institutions in the beginning as smooth. However, 
the priority given to high academic performance within the 3 years of study confined their university life to the academic arena (using an examination-oriented approach to learning), without much social life or community involvement.

\section{Transition from community college to university studies}

The NTSs perceived their transition to be relatively smooth in the beginning. The teaching modes and assessment formats were similar in the community colleges and university. These findings are consistent with those reported in the USA. ${ }^{51225}$ However, our NTSs' transition experiences might be different from their counterparts in the USA in three aspects: geographical, cultural and financial. Some American transfer students need to leave home to attend university other states; therefore, homesickness might be an issue. ${ }^{25}$ Hong Kong, however, is an urban city where public transportation is easily accessible. Therefore, travelling was not an obstacle to the transfer students in our study. Culturally, transfer students in the USA are mostly non-traditional students who are older and have family and work commitments. ${ }^{25}$ According to the American Association of Community Colleges, ${ }^{26}$ the average student age is 28 , with $38 \%$ between 22 and 39 and $9 \%$ over 40 years old. In addition, $62 \%$ of full-time students work full time or part time. On the contrary, transfer students in Asian countries are traditional students who are about the same age as their peers in the university. ${ }^{12}$ Unlike in the American culture, Asian parents make great efforts to ensure their children continue education immediately after secondary school graduation, as they see education and academic success as the avenue to upward social mobility and a better life. ${ }^{12-1427}$ As shown by these comparisons, our NTSs do not have transportation, family or work issues. However, the cultural, social and family influences can lead them to have high personal expectations to obtain high GPAs; this supports Flaga's ${ }^{25}$ suggestion that academic performance at university involves a complex set of processes.

\section{Academic adjustment as the major challenge}

Although the teaching modes and assessment formats in community college and university studies are comparable, similar to the transfer students in the USA, our NTSs soon recognised the discrepancies in terms of difficulty, academic rigour and interactions with faculty ${ }^{1225}$ Transfer students experience academic distress ${ }^{28}$ because universities expect active self-initiated learning, which requires a great deal of independent work. ${ }^{29}$ Assignments require extensive reading and critical analysis. ${ }^{12}$ However, active learning takes time. ${ }^{30}{ }^{31}$ Healthcare studies such as medicine and nursing are considered difficult programmes which require students to work hard because they have both theoretical and practical components. Transfer students in western contexts, like those in this study, engage less in social activities ${ }^{25} 2932$ However, the reasons for this might be country specific. For instance, transfer students in the USA may be less involved in campus activities due to family or work commitments, ${ }^{32}$ while our NTSs' reasons were lack of time and wanting better academic performances. According to Kember, ${ }^{33}$ Chinese students are likely to adjust their learning approaches to contextual factors in the teaching and learning environment and perceive themselves to have heavier workloads than western counterparts, for example, in Finland. ${ }^{34}$ The NTSs in our study perceived their workload to be heavy given the relatively short study time, and were therefore forced to short cut and adopt surface learning approaches as a reaction to the challenging learning environment (consistent with the literature). ${ }^{35-40}$ They did not think they had the option to use deep learning approaches because of the limited time. ${ }^{41}$ Chinese students have been found to be 'rote learners, syllabus dependent, passive and lacking in initiative' (p. 27) ${ }^{42}$ and to adopt surface learning approaches ${ }^{42}{ }^{43}$ which was conventionally associated with inferior learning outcomes in western educational research. ${ }^{33}$ However, increasing volumes of research and reports have indicated that Chinese students perform no worse than or even better than their western counterparts, ${ }^{44}$ such as in international tests (eg, programme for international student assessment (PISA). ${ }^{33}$ In his analysis, Kember ${ }^{33}$ argued that the good performances of Chinese learners are the consequence of their intermediate approaches to learning, that is, a combination of memorising and understanding, with meaningful memorisation. This is an approach in between the continuum of surface and deep approaches. On the other hand, Nield $^{45}$ found that Chinese university learners are strategic instead of rote learners. Our study supported that the NTSs were strategic learners when it came to prioritising their study efforts. Nevertheless, Chinese students are accustomed to learning through repeated practice and memorisation to achieve high grades in primary and secondary schools, where evaluation is heavily dependent on examinations, and therefore in university they tend to adopt the same learning approach, which they found to have worked well before. Studies should be conducted to explore further the learning approaches adopted by Chinese university students. Specifically, do transfer students and non-transfer students use different approaches in their learning?

\section{Implications}

To face the challenges of transition, the NTSs in this study developed strategies to balance multiple tasks. They knew how to prioritise nursing-specific subjects before general education, they sacrificed social activities and leisure time for academic studies and clinical practicums, and they attached more importance to GPA than knowledge comprehension and application. However, all these prioritisations contradict the essence of university education, which deserves attention from various parties involved in the education of transfer students, including community colleges, universities and the government. Our study has suggested that the articulation of teaching approach between community college and university is good, 
thus facilitating transfer students' initial adjustment to university study. However, more effort should be given to emphasising the alignment of subjects, which would enhance credit transfer and thus reduce the study workload. On the other hand, emphasis on deep approaches to learning could be strengthened in the community colleges, and time-management strategies targeted to the needs of transfer students (instead of just general time management techniques) should be developed to facilitate their transition. At the government policy level, guidelines should be developed to foster a positive collaborative culture between community college and university, including reviews of subject or programme alignment, with the ultimate goal of improving the numbers of subjects for credit transfers, as well as the learning experience. Furthermore, flexible or extended study periods beyond the 3 years should be encouraged, for example, by financial support from the government. Currently, the university will absorb the expenses if the students take more than 3 years to complete the study. With these strategies implemented, transfer students will have more space for their personal and professional development.

\section{Limitations}

Our study had some limitations. The participants were asked to describe their experiences since their admission to the degree programme. Recall bias or the eventual outcomes of their coping might have affected the accuracy or their interpretation of their experiences. In addition, while the participants in each focus group knew each other, which may have facilitated open discussion, some may not have felt comfortable to discuss personal concerns. Furthermore, because of the participants' availability, four of the interviews were conducted with individual participants rather than in a focus group, which might have affected the dynamics of discussion and elicitation of ideas.

\section{CONCLUSIONS}

Our study identified challenges faced by NTSs in adjusting to their university study. Suggestions are offered for different stakeholders to address the issues at individual, institutional and government levels so as to enhance NTSs' learning experiences at university.

Contributors SSYC: planned the study, drafted the methods section and revised the manuscript. LWZ: conducted data analysis, drafted the results section and revised the manuscript. GYG: conducted data collection, data analysis and revised the manuscript. KC: planned the study, coordinated the study and revised the manuscript. All authors read and approved the final manuscript.

Funding The study was funded by the University Grant Committee Funding Scheme for Teaching and Learning Related Proposals (2016-19 Triennium; PolyU6/T\&L/16 19).

Competing interests None declared.

Patient consent for publication Not required.

Ethics approval Ethical approval was obtained from the university's institutional review board (HSEARS20180104005-01).

Provenance and peer review Not commissioned; externally peer reviewed.
Data availability statement No data are available. Ethical approval does not permit data sharing. Participants did not consent to data sharing. The corresponding author can be contacted for further information.

Open access This is an open access article distributed in accordance with the Creative Commons Attribution Non Commercial (CC BY-NC 4.0) license, which permits others to distribute, remix, adapt, build upon this work non-commercially, and license their derivative works on different terms, provided the original work is properly cited, appropriate credit is given, any changes made indicated, and the use is non-commercial. See: http://creativecommons.org/licenses/by-nc/4.0/.

ORCID iD

Kin Cheung http://orcid.org/0000-0002-8419-4847

\section{REFERENCES}

1 Cameron C. Experiences of transfer students in a collaborative Baccalaureate nursing program. Community Coll Rev 2005;33:22-44.

2 Matthias AD. The intersection of the history of associate degree nursing and "BSN in 10": Three visible paths. Teaching and Learning in Nursing 2010;5:39-43.

3 American Association of Community College. Associate degree in nursing programs and AACN's support for articulation, 2019. Available: https://www.aacnnursing.org/News-Information/FactSheets/ADN-Facts [Accessed 2 Sept 2019].

4 Hills JR. Transfer shock: the academic performance of the junior College transfer. The Journal of Experimental Education 1965;33:201-15.

5 Archambault KL. The typology and needs of American transfer students. In: Sasso PA, DeVitis JL, eds. Today's college students: A reader. New York, NY: Peter Lang, 2015: 215-24.

6 Mehr KE, Daltry R. Examining mental health differences between transfer and Nontransfer university students seeking counseling services. J College Stud Psychother 2016;30:146-55.

7 Townsend BK. "Feeling like a freshman again": The transfer student transition. New Directions for Higher Education 2008;2008:69-77.

8 Santos Laanan F. Studying transfer students: Part II: dimensions of transfer students' adjustment. Community Coll $J$ Res Pract 2007;31:37-59.

9 Daltry R, Mehr KE. Examining mental health differences among transfer university students seeking counseling services. J College Stud Psychother 2016;30:262-7.

10 Chao RK. Beyond parental control and authoritarian parenting style: understanding Chinese parenting through the cultural notion of training. Child Dev 1994;65:1111-9.

11 Zhou MIN, Kim S, Forces C. Community forces, social capital, and educational achievement: the case of supplementary education in the Chinese and Korean immigrant communities. Harv Educ Rev 2006;76:1-29.

12 Ong B, Cheong KA. Juxtapose examination of experiences among transfer students in United States and current students in Malaysia. International Journal of Education 2019;4:168-78.

13 Guo K. For a better life: the aspirations of Chinese immigrants in parenting. J Immigr Refug Stud 2014;12:293-310.

$14 \mathrm{Xu} D$, Wu X. The rise of the second generation: aspirations, motivations and academic success of Chinese immigrants' children in Hong Kong. J Ethn Migr Stud 2017;43:1164-89.

15 Lee WWS. Relationships among grit, academic performance, perceived academic failure, and stress in associate degree students. $J$ Adolesc 2017;60:148-52.

16 Dyson S, McAllister M. Routledge international Handbook of nurse education. Taylor \& Francis, 2019.

$17 \mathrm{Cyr} \mathrm{J}$. The pitfalls and promise of focus groups as a data collection method. Sociol Methods Res 2016;45:231-59.

18 Vaughn S, Schumm JS, Sinagub JM. Focus group interviews in education and psychology: SAGE publications, 1996.

19 Fielding N. Varieties of research interviews. Nurse Res 1994;1:4-13.

20 Morse JM. Critical issues in qualitative research methods: SAGE publications, 1994.

21 McLafferty l. Focus group interviews as a data collecting strategy. $J$ Adv Nurs 2004;48:187-94.

22 Morse JM. The significance of saturation. Qual Health Res 1995;5:147-9.

23 Graneheim UH, Lundman B. Qualitative content analysis in nursing research: concepts, procedures and measures to achieve trustworthiness. Nurse Educ Today 2004;24:105-12.

24 Lincoln YS, Guba EG, Pilotta JJ. Naturalistic inquiry: SAGE publications. , 1985: 9, 438-9. 
25 Flaga CT. The process of transition for community College transfer students. Community College Journal of Research and Practice 2006;30:3-19.

26 American Association of Community Colleges. Fast facts, 2019. Available: https://www.aacc.nche.edu/wp-content/uploads/2019/05/ AACC2019FactSheet rev.pdf [Accessed 9 Jun 2019].

27 Louie V. Parents' aspirations and investment: the role of social class in the educational experiences of 1.5- and second-generation Chinese Americans. Harv Educ Rev 2001;71:438-75.

28 Thurmnd KC. Transfer shock: why is a term forty years old still relevant? 2007. Available: http://www.nacada.ksu.edu/Resources/ Clearinghouse/View-Articles/Dealing-with-transfer-shock.aspx [Accessed 19 Aug 2019].

29 Townsend BK, Wilson K. "A Hand Hold for A Little Bit": Factors Facilitating the Success of Community College Transfer Students to a Large Research University. J Coll Stud Dev 2006;47:439-56.

30 Felder R, Brent R. Active learning: an introduction. ASQ Higher Education Brief 2009;2:1-5.

31 Salemi MK. An illustrated case for active learning. South Econ J 2002;68:721-31.

32 Wang X. Baccalaureate attainment and College persistence of community College transfer students at four-year institutions. Res High Educ 2009;50:570-88.

33 Kember D. Why do Chinese students out-perform those from the West? do approaches to learning contribute to the explanation? Cogent Education 2016;3:1248187.

34 Hernesniemi E, Räty H, Kasanen K, et al. Perception of workload and its relation to perceived teaching and learning environments among Finnish and Chinese university students. International Journal of Higher Education 2017;6:42-55.
35 Biggs J. What do inventories of students' learning processes really measure? A theoretical review and clarification. Br J Educ Psychol 1993;63:3-19.

36 Biggs J, Tang C. Teaching for quality learning at university: what the student does. McGraw-Hill, 2007.

37 Blumberg P. Why self-directed learning is not learned and practiced in veterinary education. J Vet Med Educ 2005;32:290-5.

38 Kember D, Leung DYP. Influences upon Students' Perceptions of Workload. Educ Psychol 1998;18:293-307.

39 Parkinson TJ, Gilling M, Suddaby GT. Workload, study methods, and motivation of students within a BVSc program. J Vet Med Educ 2006;33:253-65.

40 Ryan MT, Irwin JA, Bannon FJ, et al. Observations of veterinary medicine students' approaches to study in pre-clinical years. $J$ Vet Med Educ 2004:31:242-54.

41 Chambers E. Work-Load and the quality of student learning. Studies in Higher Education 1992;17:141-53.

42 Biggs J. Approaches to learning in secondary and tertiary students in Hong Kong: some comparative studies. Education Research Journal 1991;6:27-39.

43 Sakurai Y, Pyhältö K, Lindblom-Ylänne S. Are Chinese university students more likely to exhibit a surface approach to learning than other international students in Finland? Journal of Research in International Education2014;13:135-48.

44 MIAO Yi-yiYi-yi, Miao Y. A study of the differences between China and UK classroom teaching in middle schools based on a BBC Documentary. Sino-US English Teaching 2016;13:856-9.

45 Nield K. Understanding the Chinese learner: a case study exploration of the notion of the Hong Kong Chinese learner as a Rote or strategic learner. Journal of Hospitality, Leisure, Sports and Tourism Education2007:6:39-48. 